\title{
Coherence and disparity in assessment literacies among higher education staff
}

\author{
Mark S. Davies* and Maddalena Taras - University of Sunderland, UK
}

\begin{abstract}
Assessment literacies are finding leverage, but there is little exploration of links between theory, practice and perceived understandings in higher education (HE). This article builds on and consolidates research that has taken place over ten years that evaluates assessment literacies among $\mathrm{HE}$ lecturers in education and science, and in staff developers, by presenting a comparative view of the data. The results indicate that there was generally a good understanding of theoretical and practical aspects of summative assessment across all groups. However, understandings of formative assessment showed little concordance between and within the groups, particularly among staff developers, but this group was better at clarifying the necessary link between formative assessment and feedback. Although education lecturers had a firmer grasp of central terminologies, in general there are still deficits in understanding about how these terms interrelate. Staff developers' relative weakness of understanding in some areas is of concern since this group shapes those who teach. These issues are exacerbated by a lack of acknowledgement that they exist, which may seriously hamper the development of both staff and students in clarifying processes they encounter daily. Basic shared understandings are required that can translate into personal, coherent assessment literacies. As a community we need to take on this task, because if we do not, as individuals, or individual groups, we will continue to have fragmented assessment literacies.
\end{abstract}

Keywords: assessment literacies; formative; practice; staff development; summative; theory

\section{Introduction}

This article uses empirical data on perceptions and understandings of assessment theory and links to practice that have been collected over the course of the past decade or so. The earliest article evaluated data collected from an education faculty (Taras, 2008); subsequently Taras and Davies $(2013,2014)$ analysed and evaluated data from a science faculty in the same university; finally, data were collected from staff developers from a cross-section of UK providers (Taras and Davies, 2017). The continued validity of the data is principally due to two factors. First, the theoretical literature on assessment seems to be at an impasse as little progress has been made in the last ten years, as will become evident, and, second, very few data have been collected since the studies above were published.

Our goal is to consolidate the comparable data, to draw comparisons between the data sets and, if possible, to present meaningful conclusions that have implications for both theory and practice within assessment, learning and teaching in higher education (HE) in particular. In this way we hope to enrich the ongoing debate on assessment literacy by comparing in particular the understandings of front-line 
teaching staff who shape the assessment processes with those of the people who have responsibility for training them.

\section{Background}

Recent work has begun to address the importance of assessment literacies in education more generally and HE more specifically (Price et al., 2012; Willis et al., 2013). Our work is at the core of assessment literacy in focusing on theoretical relationships of key terms and their interrelatedness, exploring how assessment literate different HE staff groups are. This helps to disentangle conceptual intricacies which may not be visible in practice.

Assessment is not an isolated concept, practice or understanding. Assessment, in any context, is a decision that is justifiable and justified (Scriven, 1967; Taras, 2012b, 2016). The justifications address the criteria and standards: these may begin as implicit in the assessor's head, but the justifications reveal not just the criteria and standards, but also personal and professional hidden agendas (Taras, 2016). Assessment is linked directly to issues of justice, which is why it needs to be justified, explicit and challengeable. It also needs to be closely contextualized and inclusive, and there needs to be a shared understanding between all the protagonists involved. Therefore, being assessment literate requires understanding of epistemologies, concepts and practices within specific and varied contexts (Taras, 2012b, 2016).

Difficulties arise in general, and in $\mathrm{HE}$ in particular, because shared understandings are not addressed systematically and inclusively: these shared understandings need to be regularly 'reinvented' and within each new group or community. As tutors we have years of experience of assessing, but this does not mean that we do not need to adapt to new circumstances. Change is not bad, but losing sight of its implications on practices and people can be very damaging.

Assessment is often seen as a subset of curriculum development, rather than as being significant in its own right, yet it is what students focus on and its outputs are central to how our universities function and are themselves assessed. Assessment is therefore of critical importance across university processes, particularly to those aspects that relate to learning and teaching, with which assessment is often viewed as a more junior partner. Thus it could be argued that assessment is the most crucial task that academics do, hence our focus, and its significant contribution to both the UK's National Student Survey (Yorke, 2013) and Teaching Excellence Framework (https:// www.officeforstudents.org.uk/advice-and-guidance/teaching/what-is-the-tef/).

Our present work contributes to an increasing body of assessment literacy literature that explores how participants in the assessment process understand and interrelate commonly used terms, though much of the earlier work did not use the term 'assessment literacy' (Maclellan, 2001, for HE, and Hargreaves, 2005, for the compulsory sector). Both Maclellan (2001) and Hargreaves (2005) explored concepts and principles of assessment and found both a general lack of alignment in understanding, and disparity between principles held and the participants' practice (Price et al., 2012; Willis et al., 2013).

Being assessment literate is necessary for educated individuals to be able to make informed and ethical choices in any given context:

Assessment literacy (in any given context) may be defined as an understanding of the issues, general and specific criteria, and standards which may enable an individual to communicate efficiently with individuals in a similar context and also to negotiate meaning (coherently) from an 
informed position, on assessments of processes or products made within that context. (Taras, in progress)

Etymologically, being literate requires an understanding of the subject in question. This definition requires clarity and understanding concerning the parameters of assessment, that is, the criteria and standards, and how assessment is carried out and contextualized with other protagonists. Thus, one important aspect of assessment literacy is a coherent and clear understanding of terms and how they interrelate. This definition thus agrees with that of Willis et al.:

the authors define teacher assessment literacies as dynamic social practices which are context dependent and which involve teachers in articulating and negotiating classroom and cultural knowledges with one another and with learners. (2013: 241)

Willis et al.'s definition is limited to educational contexts, particularly the classroom, but obviously, understanding assessment and being assessment literate is not limited to any single context.

During the last 25 years, HE discourses have moved from learning and pedagogic practice as a subject transfer paradigm - that is, the brain as an empty box to be filled - towards learning as a constructivist and social constructivist process that requires discussions and practices of inclusive pedagogic alignment and coherence. The important words are 'discourses' (what we say) and 'towards' because the alignment between assessment, learning, teaching practices and theories do not accord with many of our claims and discourses of learning centredness where students have a voice, as recent research shows.

Therefore, making it explicit and socially acceptable to share assessment literacies and discuss all aspects of assessment, judging, marking and grading will go a long way towards creating integrated curricula and uniting students and tutors as partners in learning. This is particularly true in HE but is also pertinent at all levels (Taylor and Robinson, 2009). Educational practices are perceived as requiring more direct engagement with students' inclusion in their own learning choices and this is increasingly spilling over into assessment processes and products (Berry and Adamson, 2011; Merry et al., 2013).

The importance of assessment literacies has not gone unnoticed and in December 2015 the London Review of Education ran a special issue to highlight this. The Editorial was titled 'Assessment literacy: Understanding relationships between feedback and learning' (Hughes and Hargreaves, 2015). While agreeing with the value of this focus, our work explores the relationship between all elements of assessment and how these support learning:

We are keen to promote assessment literacy for both staff and students so that assessment is more widely understood as being key to learning at all levels. (Hughes and Hargreaves, 2015: 1)

They also provide pertinent information to newcomers to the term:

Assessment literacy is not yet an established term ... We might expect that assessment literacy is not something that can be imposed or 'given' to those who undertake assessment, but is a self-directed growth in understanding of assessment purposes and processes that takes place cumulatively over time (Hughes, 2014). (lbid.) 
The desire to support student learning in the classroom, free of examinations, either internal or external, has led to the demonization of so-called summative assessment (SA) in the literature, where it is little discussed theoretically, other than to report on its potential functions. Notable exceptions are Scriven (1967) and Taras (2012b, 2016) who interrelate processes of assessment with potential functional contexts. On the other hand, discussions about formative assessment (FA) are many, although most are linked to its functions (Taras, 2012a). This ongoing debate is seen as negative by Lau (2016) and Taras (2015) because, as part of the dichotomy between SA and FA, feedback is generally only associated with FA, and much of the potential of using SA for learning is thus excluded.

Significantly, the paucity of proper engagement with the disentangling of summative and formative functions and processes, and their relationships to learning, has led to a myriad choices of meanings, which has impeded the development of assessment literate stakeholders: students, tutors, managers and those who train tutors and managers. These people are limited in their understandings precisely because of the limitations of the available theoretical frameworks, developed by those perceived to be in authority, be they researchers or those who use outputs of research to inform staff at the chalkface. Consequences of unaligned assessment theories and practice are that learners are exposed to disparate practices and sometimes theories (particularly students of education). As a result, their confidence in assessment processes is diminished, and student-inclusive assessment becomes more difficult to implement (Rust et al., 2005; Cowan, 2006; Lindblom-Ylänne et al., 2006; Smith and Sodano, 2011). SA and FA are not mutually exclusive; on the contrary, both processes are identical in that a judgement is made of the work using explicit or implicit parameters (i.e. criteria and standards) within any given context. Both SA and FA can produce grades and information for justifying the judgement and also for future improvement. The expectation is that when this information is used, it becomes formative (Taras, 2016). Therefore both SA and FA have the potential to be 'of' learning and 'for' learning. Even external examinations provide information linked to standards through the grade.

\section{Methods}

All data are based on the results of a single, well-established and piloted questionnaire comprising 44 questions (Appendix 1). Its development was discussed in Taras (2008) and as such is not further considered here.

The questionnaire was completed by 50 lecturers in education in 2007 and 50 lecturers in health and life science-related disciplines in 2010, all at the same English university. The education staff were canvassed at an away-day event and the scientists were canvassed when they met as academic teams. Eleven staff developers were canvassed in 2011 at an event concerning learning and teaching practice, and a further participant completed the questionnaire in 2012. The nature of the staff developers group is explained in full in Taras and Davies (2017): they were each from a different UK HE provider, all had national-level involvement in the external recognition of taught programmes for junior academic staff in learning and teaching, and had established institutional practice in staff development. Responses from each group in isolation have been published: educators in Taras (2008), scientists in Taras and Davies (2013, 2014) and staff developers in Taras and Davies (2017).

All participants were told that the questionnaire had to be completed anonymously and they were requested to answer the questions in order and not to go 
back. They were instructed not to confer but that they could ask for clarification of any question. No respondent took more than 15 minutes to complete the task.

In the main, the questions asked for a yes or no response, though some required written comment: questions 1 and 3 asked for a rough definition of first summative and then formative assessment; questions 2 and 4 asked for examples of summative and formative tasks, respectively; question 15 asked for the relationship between formative work and summative work; and questions 43 and 44 asked again for definitions of summative and formative assessment. For the questions requiring interpretation, key words were identified to find the general trends and the responses were classified, where possible, as 'of' or 'for' learning.

\section{Results}

In general, definitions of SA were classified as 'of learning', but some science lecturers for both the first and second definitions and one staff developer for the first definition gave responses that were classified as 'for learning', indicating a fundamental misunderstanding (Table 1). However, fewer staff developers gave a definition classified as 'of learning' for the second definition, as opposed to the first. Education lecturers made no explicit link between feedback and SA, whereas small proportions of science lecturers (second definition only) and staff developers did.

Table 1: Percentage rough definitions of SA provided that were classified as 'for' or 'of' learning, and including the word 'feedback'

\begin{tabular}{|c|c|c|c|c|c|}
\hline & Ed $\left(1^{\text {st }} \& 2^{\text {nd }}\right.$ same $)$ & Sc $1^{\text {st }}$ & Sc $2^{\text {nd }}$ & SD $1^{\text {st }}$ & SD $2^{\text {nd }}$ \\
\hline For learning & & 10 & 6 & 8 & \\
\hline Of learning & 80 & 82 & 76 & 92 & 69 \\
\hline 'Feedback' & & & 10 & 15 & 15 \\
\hline
\end{tabular}

Note: Where percentages do not sum to 100, this indicates some respondents did not answer the question or gave an ambiguous answer. Ed = education staff; Sc = science staff; SD = staff developers.

Neither science lecturers nor staff developers had the consistency of thinking shown by the education lecturers in the classification of the definition of FA (Table 2). Staff developers had a notable change in thinking, where only 69 per cent gave a clear response when asked for a second definition (and there was a parallel change in association with feedback to students). Many science lecturers were confused, giving definitions that were clearly 'of learning', more so than were confused about SA; also all links to feedback in FA disappeared in the second definition. Staff developers generally, but by no means always, associated feedback with FA, as opposed to the other groups. 'Examination' featured heavily in education lecturers' examples of SA tasks, much more so than for the other groups (Table 3).

Table 2: Percentage rough definitions of FA provided that were classified as 'for' or 'of' learning, and including the word 'feedback'

\begin{tabular}{|c|c|c|c|c|c|}
\hline & Ed ( $1^{\text {st }} \& 2^{\text {nd }}$ same $)$ & Sc $1^{\text {st }}$ & Sc $2^{\text {nd }}$ & SD $1^{\text {st }}$ & SD $2^{\text {nd }}$ \\
\hline For learning & 82 & 50 & 44 & 85 & 69 \\
\hline Of learning & & 38 & 30 & & \\
\hline 'Feedback' & 28 & 34 & & 85 & 69 \\
\hline
\end{tabular}


Table 3: Semantic focus of example of summative assessment task

\begin{tabular}{llll} 
& Ed & Sc & SD \\
\hline 'examination' & 86 & 52 & 54 \\
\hline
\end{tabular}

There was more consistency in definitions of SA than in FA across all groups (Table 4). Education lecturers showed the greatest consistency of response for both SA and FA. Science lecturers showed a considerable degree of inconsistency in both, but the greatest inconsistency was shown by staff developers for FA. In comparing first definitions with examples given, there was again more consistency for SA than FA (Table 5). Again, education lecturers were more consistent. Science lecturers showed the greatest inconsistency for SA, and staff developers for FA.

Table 4: The consistency of classified responses to the repeated questions asking for definitions of SA (questions 1 and 43) and FA (questions 3 and 44)

\begin{tabular}{lcccccc}
\hline $\begin{array}{l}\text { Classified response to } \\
\text { question } \mathbf{1} \text { or } \mathbf{3} \text { and } \mathbf{4 3}\end{array}$ & \multicolumn{3}{c}{ Definitions of SA } & \multicolumn{4}{c}{ Definitions of FA } \\
or $\mathbf{4 4}$ & Ed & Sc & SD & Ed & Sc & SD \\
\hline 'of' & 94 & 67 & 69 & & 24 & \\
'for' & & 6 & 8 & 80 & 39 & 62 \\
both & & 2 & & & 6 & \\
inconsistent & 22 & 15 & & 25 & 38 \\
unanswered & 6 & 4 & 8 & 20 & 6 & \\
\hline
\end{tabular}

Note: Numbers refer to percentage of responses that were classified according to the scheme in column 1 ('of' learning ('of'), 'for' learning ('for'), both, inconsistent response, and at least one question unanswered). Not all columns sum to 100 owing to rounding errors.

Table 5: The consistency of classified responses comparing first definitions given with examples for both SA and FA

\begin{tabular}{lcccccc}
\hline $\begin{array}{l}\text { Classified response to } \\
\text { question } \mathbf{1} \text { or } \mathbf{3} \text { and } \mathbf{2}\end{array}$ & $\begin{array}{c}\text { Definition and example } \\
\text { of SA }\end{array}$ & \multicolumn{4}{c}{ Definition and example } \\
or 4 & Ed & Sc & SD & Ed & Sc & SD \\
\hline 'of' & 80 & 41 & 69 & 2 & 31 & \\
'for' & & & & 74 & 18 & 46 \\
both & & 55 & 31 & & 4 & \\
inconsistent & 20 & 4 & & & 41 & 54 \\
unanswered & & 51 & 24 & 6 & \\
\hline
\end{tabular}

Note: Numbers refer to percentage of responses that were classified according to the scheme in column 1 ('of' learning ('of'), 'for' learning ('for'), both, inconsistent response, and at least one question unanswered). Not all columns sum to 100 owing to rounding errors.

Almost all staff use FA tasks in class, though for homework, science lecturers use FA tasks less than the other groups (Table 6). In answering questions about conflating, or not, FA and SA, each group showed consistency of thinking, and there were no clear differences between the groups and which they prefer. 
Table 6: Formative assessment tasks used with students (numbers in first row refer to question numbers)

\begin{tabular}{lccccccccccccccc}
\hline Response & $\begin{array}{c}\text { 5. FA tasks } \\
\text { used }\end{array}$ & \multicolumn{1}{c}{ 6. In class } & \multicolumn{4}{c}{ 7. For } & \multicolumn{4}{c}{ 8. FA and SA } & \multicolumn{4}{c}{ 9. FA and SA } \\
somework & \multicolumn{4}{c}{$\begin{array}{c}\text { separate } \\
\text { conflated }\end{array}$} \\
& Ed & Sc & SD & Ed & Sc & SD & Ed & Sc & SD & Ed & Sc & SD & Ed & Sc & SD \\
\hline Yes & 100 & 94 & 100 & 86 & 92 & 100 & 78 & 62 & 85 & 38 & 48 & 31 & 54 & 38 & 46 \\
No & & 6 & & 10 & 8 & & 20 & 34 & 8 & 46 & 34 & 54 & 38 & 52 & 23 \\
Sometimes & & & & & & & & & 10 & 12 & 15 & 6 & 2 & 15 \\
\hline
\end{tabular}

Most of the respondents tell students that tasks are formative, but a significant proportion either do not or do so only 'sometimes' (Table 7). The staff developers always explain how a task is formative but the other groups often do not do this. Education and science lecturers generally either always mark or always do not mark formative work, but staff developers were not as rigid: about a third responding 'sometimes' and far fewer always marked formative work. Similarly, staff developers were more flexible in grading formative work and fewer always graded formative work. Most respondents regarded formative work as related to summative work, and some education and science lecturers regarded them as unrelated. Again staff developers showed flexibility in that approximately a quarter recognized that a relationship may exist dependent on circumstances.

In describing how FA and SA are related, approximately three-quarters (76 per cent) of education lecturers, two-thirds (69 per cent) of staff developers but only onethird (32 per cent) of science lecturers regarded FA as leading to SA (Table 7).

Table 7: Information given to students on formative assessment tasks

\begin{tabular}{lccccccccccccccc}
\hline Response & $\begin{array}{c}\text { 11. Tell } \\
\text { students } \\
\text { task is FA }\end{array}$ & $\begin{array}{c}\text { 12. Explain } \\
\text { how task is }\end{array}$ & $\begin{array}{c}\text { 13. Is } \\
\text { formative } \\
\text { work } \\
\text { marked? }\end{array}$ & $\begin{array}{c}\text { 14. Is } \\
\text { formative } \\
\text { work } \\
\text { graded? }\end{array}$ & $\begin{array}{c}\text { 15. Is } \\
\text { formative } \\
\text { work } \\
\text { related to } \\
\text { summative } \\
\text { work? }\end{array}$ \\
\hline Yes & Ed & Sc & SD & Ed & Sc & SD & Ed & Sc & SD & Ed & Sc & SD & Ed & Sc & SD \\
\hline No & 70 & 78 & 69 & 64 & 74 & 100 & 70 & 66 & 38 & 30 & 48 & 23 & 78 & 70 & 77 \\
Sometimes & 30 & 18 & 8 & 36 & 22 & & 24 & 32 & 31 & 58 & 48 & 38 & 10 & 18 & \\
\hline
\end{tabular}

Most respondents claimed to use student self-assessment (ssa) (Table 8). Staff developers, in comparison to the other two groups, seem to shy away from using ssa as a summative exercise, preferring to use it formatively, though no group indicated heavy use of ssa summatively. Only about one-third of all respondents thought that ssa involves both SA and FA (Table 8).

Most respondents, though a slightly lower proportion of staff developers, agreed that theory is important for teachers (Table 9). 
Table 8: Information on student self-assessment (ssa)

\begin{tabular}{|c|c|c|c|c|c|c|c|c|c|c|c|c|}
\hline \multirow[t]{2}{*}{ Response } & \multicolumn{3}{|c|}{$\begin{array}{l}\text { 17. Do students } \\
\text { do ssa? }\end{array}$} & \multicolumn{3}{|c|}{$\begin{array}{l}\text { 18. Do you } \\
\text { present ssa as } \\
\text { a formative } \\
\text { exercise? }\end{array}$} & \multicolumn{3}{|c|}{$\begin{array}{l}19 . \text { Do you } \\
\text { present ssa as } \\
\text { a summative } \\
\text { exercise? }\end{array}$} & \multicolumn{3}{|c|}{$\begin{array}{c}\text { 20. Does ssa } \\
\text { use both SA and } \\
\text { FA? }\end{array}$} \\
\hline & Ed & Sc & SD & Ed & Sc & SD & Ed & Sc & SD & Ed & Sc & SD \\
\hline Yes & 70 & 56 & 77 & 58 & 46 & 69 & 28 & 20 & 15 & 30 & 34 & 31 \\
\hline No & 28 & 44 & 15 & 36 & 50 & 8 & 60 & 72 & 62 & 66 & 50 & 46 \\
\hline Sometimes & 2 & & & 4 & & 8 & 4 & 2 & 8 & 2 & & 8 \\
\hline
\end{tabular}

Table 9: Agreed that theory is 'important to us as teachers'

\begin{tabular}{ccc}
\hline Ed & Sc & SD \\
\hline 96 & 90 & 85 \\
\hline
\end{tabular}

Almost all respondents agreed that SA can be used for end-of-course grades, and a significant majority that SA can be used for mid-course grades (Table 10). However, across all groups, between 20 and 26 per cent thought SA could not be used for midcourse grades. Staff developers were more reluctant to use FA for end-of-course or mid-course grades than the other two groups (Table 10).

Most respondents regarded SA as assessing product and FA as assessing process (Table 11). Nevertheless, a significant minority of science lecturers disagreed that SA assesses product, and significant minorities of all groups disagreed that FA assesses product. There was much less consensus in answers to questions asking whether or not SA assesses process and FA assesses product, with many respondents answering 'no' to each question.

Table 10: Summative and formative assessment can be used for end- or mid-course grades

\begin{tabular}{|c|c|c|c|c|c|c|c|c|c|c|c|c|}
\hline \multirow[t]{2}{*}{ Response } & \multicolumn{3}{|c|}{$\begin{array}{l}\text { 22. SA can be } \\
\text { used for end-of- } \\
\text { course grades }\end{array}$} & \multicolumn{3}{|c|}{$\begin{array}{l}\text { 23. FA can be } \\
\text { used for end-of- } \\
\text { course grades }\end{array}$} & \multicolumn{3}{|c|}{$\begin{array}{l}\text { 24. SA can be } \\
\text { used for mid- } \\
\text { course grades }\end{array}$} & \multicolumn{3}{|c|}{$\begin{array}{l}\text { 25. FA can be } \\
\text { used for mid- } \\
\text { course grades }\end{array}$} \\
\hline & Ed & Sc & SD & Ed & Sc & SD & Ed & Sc & SD & $\mathrm{Ed}$ & Sc & SD \\
\hline Yes & 98 & 82 & 100 & 56 & 40 & 31 & 76 & 70 & 69 & 66 & 54 & 38 \\
\hline No & 2 & 16 & & 40 & 54 & 69 & 20 & 26 & 23 & 32 & 44 & 53 \\
\hline Sometimes & & & & & 4 & & & 2 & 8 & & & 8 \\
\hline
\end{tabular}

Table 11: Summative and formative assessment assess product and/or process

\begin{tabular}{|c|c|c|c|c|c|c|c|c|c|c|c|c|}
\hline \multirow[t]{2}{*}{ Response } & \multicolumn{3}{|c|}{$\begin{array}{l}\text { 26. SA assesses } \\
\text { product }\end{array}$} & \multicolumn{3}{|c|}{$\begin{array}{l}\text { 27. SA assesses } \\
\text { process }\end{array}$} & \multicolumn{3}{|c|}{$\begin{array}{l}\text { 28. FA assesses } \\
\text { product }\end{array}$} & \multicolumn{3}{|c|}{$\begin{array}{l}\text { 29. FA assesses } \\
\text { process }\end{array}$} \\
\hline & $\mathrm{Ed}$ & $\mathrm{Sc}$ & SD & $\mathrm{Ed}$ & $\mathrm{Sc}$ & SD & $\mathrm{Ed}$ & $\mathrm{Sc}$ & SD & $\mathrm{Ed}$ & Sc & SD \\
\hline Yes & 90 & 76 & 100 & 58 & 62 & 92 & 70 & 66 & 46 & 86 & 80 & 100 \\
\hline No & & 20 & & 30 & 32 & 8 & 14 & 28 & 31 & 10 & 16 & \\
\hline Sometimes & 6 & & & 6 & & & 6 & 2 & 8 & 4 & 2 & \\
\hline
\end{tabular}


Most respondents recognized that SA assesses for validation, but approximately onethird of science lecturers believed that it did not (Table 12). A lower proportion of staff developers recognized that SA assesses for learning than did either group of lecturers, although there was still some doubt. There was general agreement that FA assesses for learning, but a large degree of uncertainty across all groups about whether FA assesses for validation. As expected, FA was seen as providing useful feedback by almost all respondents (Table 13).

Table 12: Summative and formative assessment assess for validation (grading) or for learning

\begin{tabular}{lcccccccccccc}
\hline Response & \multicolumn{3}{c}{ 30. SA assesses } & \multicolumn{3}{c}{ 31. SA assesses } & \multicolumn{3}{c}{ 32. FA assesses } & \multicolumn{3}{c}{ 33. FA assesses } \\
& for validation & \multicolumn{2}{c}{ for learning } & \multicolumn{2}{c}{ for validation } & \multicolumn{2}{c}{ for learning } \\
& Ed & Sc & SD & Ed & Sc & SD & Ed & Sc & SD & Ed & Sc & SD \\
\hline Yes & 84 & 62 & 69 & 78 & 78 & 69 & 48 & 52 & 46 & 90 & 90 & 92 \\
No & 4 & 30 & & 12 & 18 & & 40 & 40 & 31 & & 8 & \\
Sometimes & 6 & & 8 & 6 & & 23 & 6 & & 8 & 2 & & 8 \\
\hline
\end{tabular}

Table 13: Summative and formative assessment provide useful feedback

\begin{tabular}{lrrrrrr}
\hline Response & \multicolumn{3}{c}{ 34. SA provides } & \multicolumn{3}{c}{ 35. FA provides } \\
& \multicolumn{2}{c}{ useful feedback } & \multicolumn{2}{c}{ useful feedback } \\
& Ed & Sc & SD & Ed & Sc & SD \\
\hline Yes & 82 & 78 & 77 & 96 & 88 & 100 \\
No & 12 & 18 & 8 & 2 & 8 & \\
Sometimes & 6 & 2 & 15 & 2 & & \\
\hline
\end{tabular}

Most recognized that SA can be used to provide useful feedback, particularly the education lecturers. Though SA usually results in the provision of a grade, a minority of each group did not equate this with useful feedback to students, although there was some doubt.

The staff developers regarded SA and FA as more similar and less different processes than did the lecturers (Table 14). In particular the education lecturers found SA and FA more different and less similar processes than the other groups. Education lecturers were most confident that they knew how FA and SA related to each other, and science lecturers the least confident (Table 15). However, a significant minority from each group chose not to answer the question.

Most respondents thought students understand SA, but fewer thought students understand FA, especially the staff developers (Table 16). While most respondents thought students focus on SA, including all the staff developers, less than a third of respondents in each group thought students focused on FA, and only one staff developer. 
Table 14: Summative and formative assessment are different or similar processes

\begin{tabular}{|c|c|c|c|c|c|c|}
\hline \multirow[t]{2}{*}{ Response } & \multicolumn{3}{|c|}{$\begin{array}{c}\text { 36. SA and FA } \\
\text { are different } \\
\text { processes }\end{array}$} & \multicolumn{3}{|c|}{$\begin{array}{l}\text { 37. SA and FA } \\
\text { are similar } \\
\text { processes }\end{array}$} \\
\hline & Ed & $\mathrm{Sc}$ & SD & Ed & $\mathrm{Sc}$ & SD \\
\hline Yes & 68 & 50 & 38 & 50 & 64 & 85 \\
\hline No & 22 & 42 & 46 & 30 & 30 & 15 \\
\hline Sometimes & 6 & 4 & 8 & 12 & 4 & \\
\hline
\end{tabular}

Table 15: Are you sure how SA and FA relate to each other?

\begin{tabular}{lccc}
\hline Response & Ed & Sc & SD \\
\hline Yes & 80 & 46 & 69 \\
No & 4 & 22 & 15 \\
Did not answer & 16 & 32 & 15 \\
\hline
\end{tabular}

Table 16: Students understand and focus on summative and formative assessment

\begin{tabular}{lcccccccccccc}
\hline Response & \multicolumn{3}{c}{$\begin{array}{l}\text { 39. Students } \\
\text { understand SA }\end{array}$} & \multicolumn{3}{c}{ 40. Students } & \multicolumn{3}{c}{ 41. Students } & \multicolumn{3}{c}{ 42. Students } \\
& Ed & Sc & SD & Ed & Sc & SD & Ed & Sc & SD & Ed & Sc & SD \\
\hline Yes & 74 & 72 & 77 & 60 & 50 & 38 & 82 & 76 & 100 & 32 & 28 & 8 \\
No & 10 & 28 & 8 & 26 & 48 & 38 & 12 & 22 & & 50 & 64 & 77 \\
Sometimes & 16 & & 15 & 14 & 2 & 20 & 2 & 2 & & 14 & 4 & 15 \\
\hline
\end{tabular}

\section{Discussion}

Though it is positive that most respondents identified SA as being 'of learning', it is odd that staff developers seemed less certain about SA at the second definition - only 69 per cent responded (Table 1). This may show the impact of the questionnaire on their thinking: 31 per cent were unable to commit themselves clearly. In general there was a dearth of association between SA and feedback to students. Given the current state of understanding about assessment and assessment theory, where sometimes SA is isolated from feedback and FA (Taras, 2012a,b), it is nevertheless gratifying that a few science lecturers and staff developers still believe that all assessment has useful feedback potential. It is, however, surprising that so few staff developers and no education lecturers made a connection.

The literature universally associates the necessity of feedback with FA (Sadler, 1989; Taras, 2009; Black and Wiliam, 2009) and this is strongly evident in staff developer responses to definitions of $F A$, but it is of concern that lecturing staff do not reflect this position.

There seems a recognition among the science lecturers and staff developers that SA tasks need not be examinations, whereas education lecturers strongly associate SA with examinations, which perhaps reflects practice in the compulsory sector. Greater consistency in definitions of SA (Table 4) may indicate more rigid views than of FA, which seems a more fluid concept from our results. 
The increased consistency between definitions and examples in SA (Table 5) again points to SA being a more fixed and better understood concept. The erroneous definitions of SA and FA coupled with inconsistencies in definitions and examples suggest that many staff across all groups tested have little expertise in assessment, especially its theory and principles. The inconsistency from staff developers in the understanding of FA is a concern since these staff are involved in shaping the understandings of other staff. This may, to some extent, explain the lack of understanding in the other staff groups, though education lecturers are clearly not so influenced and perhaps their understandings originate elsewhere, for example in the compulsory sector.

We found that FA tasks are more commonly found in classroom work than homework, aligning with the assessment for learning literature, where FA is typically regarded as a classroom activity (Gardner, 2006; Stobart, 2008; Berry and Adamson, 2011). Most but not all assessments in HE conflate FA and SA, the exceptions typically being unseen examinations and end-of-course research projects, thus it was surprising that few respondents reported conflation or separation only 'sometimes'. Also about half the staff developers reported that they conflate FA and SA, yet in their roles in working with academic staff a value approaching 100 per cent would seem more logical. Much assessment for learning literature originating in the compulsory sector recognizes the desirability of separating SA and FA functions (Black et al., 2003; Gardner, 2006; Wiliam, 2009; Havnes and McDowell, 2008; Stobart, 2008; Black and Wiliam, 2009) so it is surprising that more education lecturers conflate SA and FA than separate them. Using SA tasks for learning through feedback has always been a prerogative of higher education and reduces unnecessary duplication (Taras, 2012b), although this is also very important in the compulsory sector, particularly in classroom assessment (Black, 2015).

In terms of information given to students on FA the staff developers are far more flexible in their approach, perhaps reflecting a more mature understanding of assessment. Also staff developers show good practice in always explaining to their students how tasks are FA. A significant proportion of all respondents excluded grading from FA (Table 7), in accordance with some literature stemming from the compulsory sector (Black et al., 2003), and there may be an over-reliance on this literature in the absence of HE-specific literature. Without grading it is more difficult for students to understand their own position against established criteria and standards (Taras, 2015). The notion that FA leads to SA is founded in the compulsory sector (Black et al., 2003; Black and Wiliam, 2009; Wiliam, 2007, 2009), where the concepts of FA and SA are based on functions and technically have no relevance to uses and processes, which are in discussion here (Taras, 2012 a, b). The penetration of compulsory sector thinking into $\mathrm{HE}$ is perhaps demonstrated by the much higher identification of FA leading to SA by education lecturers and staff developers.

There was a general reluctance to use ssa summatively (Table 8), perhaps related to the risk of involving students and the association in the literature between FA and ssa (Sadler, 1989; Black and Wiliam, 2009) and generally excluding the link between SA and ssa (Taras, 2012a, 2015). The highest level of reluctance was shown by the staff developers, which is surprising, given that they are recognized as specialists in $\mathrm{HE}$ learning and teaching. It is possible that expertise in learning and teaching does not necessarily indicate expertise in assessment. The implications for practice of excluding students from assessment are enormous in a sector which purports to be learner-centred. 
Although most respondents agreed on the importance of theory (Table 9), in general other responses did not indicate a strong understanding or utilization of this theory in practice. A minority of staff developers regarded theory as unimportant, seemingly disregarding the notion that theory is necessary to explain and allow the improvement of practice.

Some respondents thought that SA could not be used for end-of-course and mid-course grades (including 23 per cent of staff developers; Table 10). This bears no relevance to either theory or practice. There is apparent disjunction in the relationship between FA and grading across the board. Eliminating the possibility of FA in end-ofcourse grading is counter to discourses of lifelong learning and progression.

The separation in assessing process and product as regards FA and SA generally reported and exemplified by the staff developers (Table 11) indicates an erroneous link of product with SA and process with FA. The literature is silent on such links so where these discrepancies arise from is unclear. Both SA and FA can, of course, assess both process or product (Taras, 2009, 2012b, 2016).

In respect of the questions relating to validation and learning, a lack of consistency was clearly evident in understanding the relationships between SA and FA functions. Any assessment can be used for a wide variety of functions, including for validation and for learning, whether the focus be on FA or SA. Worryingly, our results from all groups seemed to negate this. By not acknowledging that summative work is useful for both validation and learning, lecturers will miss opportunities to use such assessments to improve students' learning. There is a significant implication for practice here, especially given the stance taken by the staff developers. Though there is nothing to suggest that SA cannot provide useful feedback to students, the lowest proportion not recognizing this was from the staff developers (Table 13), suggesting they are limited in their thinking and understanding by the rhetoric of fixed categorization of terms.

Though staff developers in particular regarded FA and SA as generally similar processes (Table 14), they identified significant differences in their responses to other questions comparing FA and SA, perhaps reflecting the generic nature of any assessment process. That education lecturers regard SA and FA as most distinct may reflect the assessment literature stemming from the compulsory sector (Taras, 2012a). The education lecturers' and staff developers' confidence in understanding how SA and FA relate to each other (Table 15) was not borne out by their answers to other questions, thus they may be overconfident in their beliefs. Science lecturers were least confident and perhaps more honest, given that they had been able to evaluate their own understandings through completion of the questionnaire thus far. The general confusion is indicated by the relatively large proportions that refused to answer the question.

That a low proportion of staff developers in particular thought their students understood FA (Table 16) might be explained by the nature of the group they regard as students. They may have been referring to the lecturers that they teach as their student group. If so, this is an admission that they have been ineffective in promoting shared understanding of terms. In any case smaller proportions thought students understood FA rather than SA and this may reflect student focus on graded activities and a poor understanding of the purpose of FA or engagement with it. Our data confirm the generally held belief among staff that students focus on SA and not FA. Whether this belief is realized in the respondents' students is unknown. However, that about a third of lecturers believe that their students do focus on FA is encouraging; again, the very low proportion of staff developers believing this may reflect their lack of confidence in 
their potentially different student group. More generally there is an issue in that staff are not communicating the nature of SA and FA to their students, which might be explicable if staff themselves do not fully understand these terms and issues.

Irrespective of the student group or the staff delivering in, for example science or performing arts, at all educational levels, in all cultural contexts, and whether the students are undergraduates or staff members, the relationships between SA and FA and processes and functions remain the same. As such, contextual factors do not - and should not - impinge on understandings of assessment theory and practice.

Assessment seems increasingly to have taken two quite divergent and distinct routes which are being treated as two dichotomous and distinct types. On the one hand, there are product or process assessments often linked to so-called SA and, on the other, 'classroom assessment', variously called FA, which is part of the interaction of learning and teaching and which does not seem to be made to follow the same rules as the product assessment, which is graded and used for validation or accreditation. SA has been demonized as the negative face of assessment and FA as the positive face. This SA and FA dichotomy had its origins in Bloom et al. (1971) and their interpretation of Scriven (1967). Lau (2016) evaluates and maps the development of this dichotomy for HE and comes to the same conclusions as Taras $(2007,2012 a, 2016)$ and Taras and Davies (2017) who have examined both the HE sector and also the compulsory K12 sector by evaluating the work of Black and Wiliam $(1998,2009)$ and researchers forming part of the Assessment Reform Group (ARG), including Gardner (2006) and Stobart (2008). Black and Wiliam (1998) justified their exclusion of SA research from their review by stating they wished to focus on assessment that supports learning. This stance was consolidated in Black et al. (2003), which is used extensively in teacher education in the UK.

Overall, we revealed a general lack of conformity of understanding, both across and within the groups, for example in distinguishing between process and product, and in the lack of specificity and transparency of processes of assessment. Clearly there are significant issues here, but there is some lack of appreciation or acknowledgement that these issues exist (Table 15) and this may be seriously hampering the development of both staff and students in clarifying the processes they encounter daily. Possible mechanisms to overcome the lack of communal assessment literacies involve communicating and agreeing on our discourses, and relating the discourses to our practices and the implications for both theory and practice. This requires an unpicking and agreed understanding of theory. Only then can we move forward with transmitting our coherent discourses to tutors and students and involving them in understandings that will improve their learning. There is a long way to go in HE in developing basic, shared understandings that can translate into and lead to personal coherent assessment literacies. As a community we need to take on this task, because, unless we do, as individuals or individual groups, we will continue to have fragmented assessment literacies.

\section{Notes on the contributors}

Maddalena Taras is a researcher whose work focuses on a range of assessment issues: self-assessment in terms of developing an original framework and examining issues of power; institutional discrepancies and contradictions in assessment practices and discourses; constraints from language, culture and power impacting on assessment perceptions and practices; and critiquing the notion of 'assessment for learning', particularly the theoretical framework. 
Mark S. Davies is a biologist with a large portfolio of activities relating to learning and teaching and its management in higher education. His research in education, besides assessment, concerns formulating strategies for student retention and the use of computer simulations in teaching complex subjects.

\section{References}

Berry, R. and Adamson, B. (eds) (2011) Assessment Reform in Education: Policy and practice. Dordrecht: Springer.

Black, P. (2015) 'Formative assessment - an optimistic but incomplete vision'. Assessment in Education: Principles, Policy and Practice, 22(1), 161-77.

Black, P., Harrison, C., Lee, C., Marshall, B. and Wiliam, D. (2003) Assessment for Learning: Putting it into practice. Maidenhead: Open University Press.

Black, P. and Wiliam, D. (1998) 'Assessment and classroom learning'. Assessment in Education: Principles, Policy and Practice, 5 (1), 7-74.

Black, P. and Wiliam, D. (2009) 'Developing the theory of formative assessment'. Educational Assessment, Evaluation and Accountability, 21 (1), 5-31.

Bloom, B.S., Hastings, J.T. and Madaus, G.F. (1971) Handbook on Formative and Summative Evaluation of Student Learning. New York: McGraw-Hill.

Cowan, J. (2006) On Becoming an Innovative University Teacher: Reflection in action. 2nd ed. Maidenhead: Open University Press.

Gardner, J. (ed.) (2006) Assessment and Learning. London: SAGE Publications.

Hargreaves, E. (2005) 'Assessment for learning? Thinking outside the (black) box'. Cambridge Journal of Education, 35 (2), 213-24.

Havnes, A. and McDowell, L. (eds) (2008) Balancing Dilemmas in Assessment and Learning in Contemporary Education. New York: Routledge.

Hughes, G. (2014) Ipsative Assessment: Motivation through marking progress. Basingstoke: Palgrave Macmillan.

Hughes, G. and Hargreaves, E. (2015) 'Assessment literacy: Understanding relationships between feedback and learning'. London Review of Education, 13 (3), 1-2.

Lau, A.M.S. (2016) "'Formative good, summative bad?": A review of the dichotomy in assessment literature'. Journal of Further and Higher Education, 40 (4), 509-25.

Lindblom-Ylänne, S., Trigwell, K., Nevgi, A. and Ashwin, P. (2006) 'How approaches to teaching are affected by discipline and teaching context'. Studies in Higher Education, 31 (3), 285-98.

Maclellan, E. (2001) 'Assessment for learning: The differing perceptions of tutors and students'. Assessment and Evaluation in Higher Education, 26 (4), 307-18.

Merry, S., Price, M., Carless, D. and Taras, M. (eds) (2013) Reconceptualising Feedback in Higher Education: Developing dialogue with students. London: Routledge.

Price, M., Rust, C., O’Donovan, B., Handley, K. and Bryant, R. (2012) Assessment Literacy: The foundation for improving student learning. Oxford: Oxford Centre for Staff and Learning Development.

Rust, C., O'Donovan, B. and Price, M. (2005) 'A social constructivist assessment process model: How the research literature shows us this could be best practice'. Assessment and Evaluation in Higher Education, 30 (3), 231-40.

Sadler, D.R. (1989) 'Formative assessment and the design of instructional systems'. Instructional Science, 18 (2), 119-44.

Scriven, M. (1967) 'The methodology of evaluation'. In Tyler, R.W., Gagné, R.M. and Scriven, M. (eds) Perspectives of Curriculum Evaluation. Chicago: Rand McNally, 39-83.

Smith, C.M. and Sodano, T.M. (2011) 'Integrating lecture capture as a teaching strategy to improve student presentation skills through self-assessment'. Active Learning in Higher Education, $12(3), 151-62$.

Stobart, G. (2008) Testing Times: The uses and abuses of assessment. London: Routledge.

Taras, M. (2007) 'Assessment for learning: Understanding theory to improve practice'. Journal of Further and Higher Education, 31 (4), 363-71.

Taras, M. (2008) 'Summative and formative assessment: Perceptions and realities'. Active Learning in Higher Education, 9 (2), 172-92.

Taras, M. (2009) 'Summative assessment: The missing link for formative assessment'. Journal of Further and Higher Education, 33 (1), 57-69. 
Taras, M. (2012a) 'Where is the theory in assessment for learning?'. Online Educational Research Journal. Online. http://community.dur.ac.uk/p.b.tymms/oerj/publications/46.pdf (accessed 19 July 2018).

Taras, M. (2012b) 'Assessing assessment theories'. Online Educational Research Journal. Online. http://community.dur.ac.uk/p.b.tymms/oerj/publications/50.pdf (accessed 19 July 2018).

Taras, M. (2015) Innovative Pedagogical Practices: Innovations in student-centred assessment. Online. www.heacademy.ac.uk/innovations-student-centred-assessment (accessed 12 December 2017). Commissioned for Innovative Pedagogies project HEA.

Taras, M. (2016) 'Assessment - summative and formative - some theoretical reflections'. In Malloch, M., Cairns, L. and O'Connor, B.N. (eds) Learning and Teaching in Higher Education: Volume 4: Assessment and evaluation in higher education. London: SAGE Publications, 466-78.

Taras, M. and Davies, M.S. (2013) 'Perceptions and realities in the functions and processes of assessment'. Active Learning in Higher Education, 14 (1), 51-61.

Taras, M. and Davies, M.S. (2014) 'Perceptions and realities in assessment definitions and uses'. International Research in Education, 2 (1), 103-17.

Taras, M. and Davies, M.S. (2017) 'Assessment beliefs of higher education staff developers'. London Review of Education, 15 (1), 126-40.

Taylor, C. and Robinson, C. (2009) 'Student voice: Theorising power and participation'. Pedagogy, Culture and Society, 17 (2), 161-75.

Wiliam, D. (2007) 'Keeping learning on track, classroom assessment and the regulation of learning'. In Lester, F.K. (ed.) Second Handbook of Research on Mathematics Teaching and Learning Charlotte, NC: Information Age Publishing, 1053-98.

Wiliam, D. (2009) Assessment for Learning: Why, what and how? London: Institute of Education.

Willis, J., Adie, L. and Klenowski, V. (2013) 'Conceptualising teachers' assessment literacies in an era of curriculum and assessment reform'. Australian Educational Researcher, 40 (2), 241-56.

Yorke, M. (2013) 'Surveys of "the student experience" and the politics of feedback'. In Merry, S., Price, M., Carless, D. and Taras, M. (eds) Reconceptualising Feedback in Higher Education: Developing dialogue with students. London: Routledge, 6-18. 


\section{Appendix 1}

\section{Questionnaire on summative and formative assessment}

Where 'YES - NO' or 'SURE - NOT SURE' is presented, please circle your choice.

1. Give a rough definition of summative assessment.

2. Give an example of a summative assessment task.

3. Give a rough definition of formative assessment.

4. Give an example of a formative assessment task.

5. Do you use formative assessment tasks with your students? YES - NO

6. Do you use formative assessment tasks in class? YES - NO

7. Do you use formative assessment tasks for homework? YES - NO

8. Do you keep summative and formative tasks separate? YES - NO

9. Do you conflate summative and formative tasks? YES - NO

10. If yes, give an example.

If you use formative assessment with your students:

11. Do you tell them it will be a formative assessment? YES - NO

12. Do you explain how it will be a formative assessment? YES - NO

13. Is formative work marked? YES - NO

14. Is formative work graded? YES - NO

15. Is formative work related to summative work? YES - NO

16. If yes, how is it related?

17. Do your students carry out self-assessment? YES - NO

18. Do you present self-assessment as a formative exercise? YES - NO

19. Do you present self-assessment as a summative exercise? YES - NO

20. Does self-assessment use both summative and formative assessment? YES - NO

21. Is theory important to us as teachers? YES - NO

22. Summative assessment can be used for end-of-course grades. YES - NO

23. Formative assessment can be used for end-of-course grades. YES - NO

24. Summative assessment can be used for mid-course grades. YES - NO

25. Formative assessment can be used for mid-course grades. YES - NO

26. Summative - assesses product. YES - NO

27. Summative - assesses process. YES - NO

28. Formative - assesses product. YES - NO

29. Formative - assesses process. YES - NO

30. Summative - assesses for validation. YES - NO

31. Summative - assesses for learning. YES - NO

32. Formative - assesses for validation. YES - NO

33. Formative - assesses for learning. YES - NO

34. Summative provides useful feedback. YES - NO

35. Formative provides useful feedback. YES - NO

36. Summative and formative are different processes. YES - NO

37. Summative and formative are similar processes. YES - NO

38. I am SURE - NOT SURE how summative and formative relate to each other.

39. Students understand summative assessment. YES - NO

40. Students understand formative assessment. YES - NO 
41. Students focus on summative assessment. YES - NO

42. Students focus on formative assessment. YES - NO

43. Without looking back, give a definition of summative assessment.

44. Without looking back, give a definition of formative assessment.

Thank you very much for your time and brain power. 